\title{
Rationally designed anionic diblock copolymer worm gels are useful model systems for calcite occlusion studies
}

DOI:

10.1039/C9PY00889F

\section{Document Version}

Accepted author manuscript

Link to publication record in Manchester Research Explorer

\section{Citation for published version (APA):}

Fielding, L. A., Hendley IV, C. T., Asenath-Smith, E., Estroff, L. A., \& Armes, S. P. (2019). Rationally designed anionic diblock copolymer worm gels are useful model systems for calcite occlusion studies. Polymer Chemistry. https://doi.org/10.1039/C9PY00889F

\section{Published in:}

Polymer Chemistry

\section{Citing this paper}

Please note that where the full-text provided on Manchester Research Explorer is the Author Accepted Manuscript or Proof version this may differ from the final Published version. If citing, it is advised that you check and use the publisher's definitive version.

\section{General rights}

Copyright and moral rights for the publications made accessible in the Research Explorer are retained by the authors and/or other copyright owners and it is a condition of accessing publications that users recognise and abide by the legal requirements associated with these rights.

\section{Takedown policy}

If you believe that this document breaches copyright please refer to the University of Manchester's Takedown Procedures [http://man.ac.uk/04Y6Bo] or contact uml.scholarlycommunications@manchester.ac.uk providing relevant details, so we can investigate your claim.

\section{OPEN ACCESS}



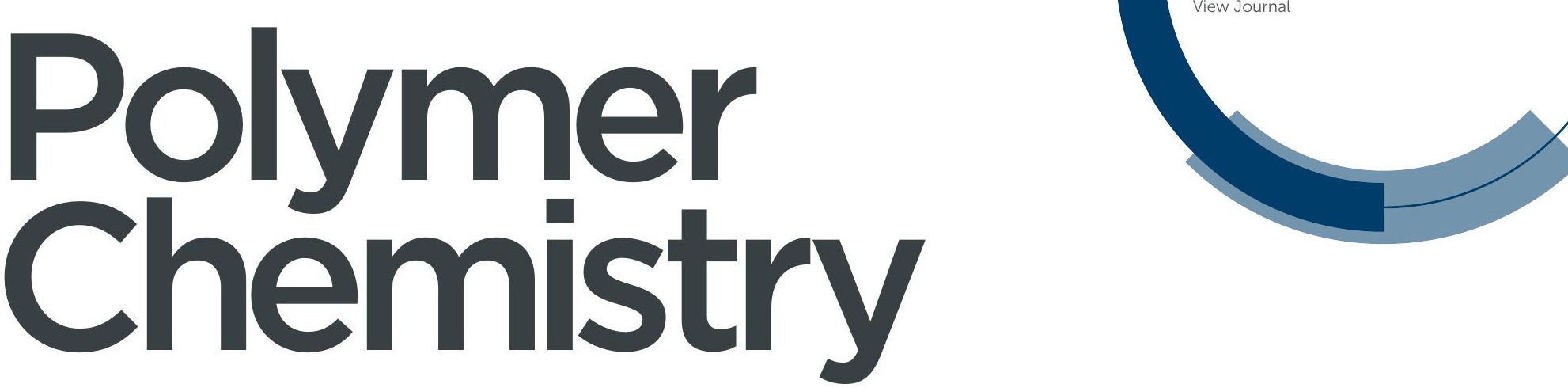

\section{Accepted Manuscript}

This article can be cited before page numbers have been issued, to do this please use: L. A. Fielding, C. Hendley, E. Asenath-Smith, L. A. Estroff and S. P. Armes, Polym. Chem., 2019, DOI: 10.1039/C9PY00889F.

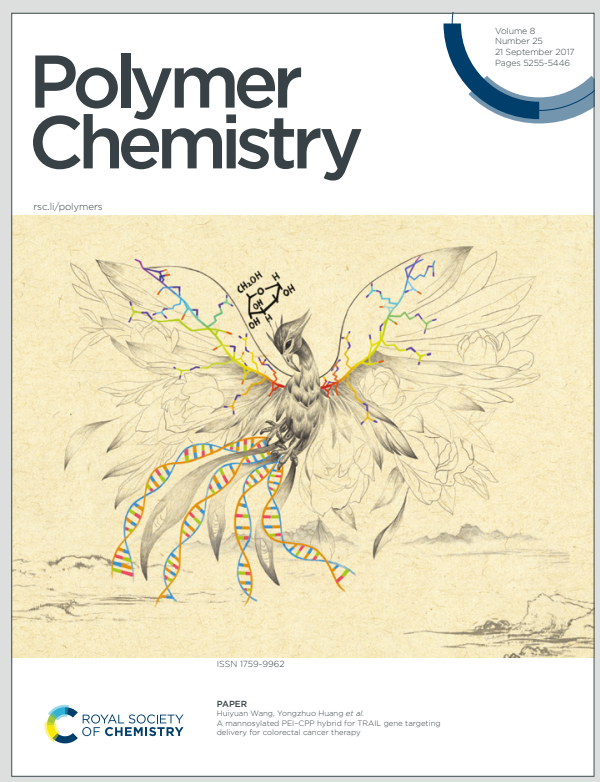

This is an Accepted Manuscript, which has been through the Royal Society of Chemistry peer review process and has been accepted for publication.

Accepted Manuscripts are published online shortly after acceptance, before technical editing, formatting and proof reading. Using this free service, authors can make their results available to the community, in citable form, before we publish the edited article. We will replace this Accepted Manuscript with the edited and formatted Advance Article as soon as it is available.

You can find more information about Accepted Manuscripts in the Information for Authors.

Please note that technical editing may introduce minor changes to the text and/or graphics, which may alter content. The journal's standard Terms \& Conditions and the Ethical guidelines still apply. In no event shall the Royal Society of Chemistry be held responsible for any errors or omissions in this Accepted Manuscript or any consequences arising from the use of any information it contains. 


\section{Journal Name}

\section{ARTICLE}

\section{Rationally designed anionic diblock copolymer worm gels are useful model systems for calcite occlusion studies}

Received 00th January 20xx, Accepted 00th January 20xx

DOI: $10.1039 / \times 0 \times x 00000 x$

www.rsc.org/

\author{
Lee A. Fielding, ${ }^{a, *}$ Coit T. Hendley IV,${ }^{b}$ Emily Asenath-Smith, ${ }^{b, c}$ Lara A. Estroff ${ }^{b}$ and Steven P. Armes ${ }^{d}$
}

Binary mixtures of anionic and non-ionic macromolecular chain transfer agents (macro-CTAs) are utilized in order to rationally design diblock copolymer nanoparticles with tunable morphologies and anionic character via pseudo-living radical polymerization. More specifically, poly(methacrylic acid) (PMAA) and poly(glycerol monomethacrylate) (PGMA) macro-CTAs are pre-mixed prior to reversible addition-fragmentation chain transfer (RAFT) aqueous dispersion polymerization of 2hydroxypropyl methacrylate (HPMA). This strategy facilitates the formation of PHPMA-based diblock copolymer spheres, worm-like micelles and vesicles via polymerization-induced self-assembly (PISA). The presence of the anionic PMAA stabilizer block has a dramatic impact on the resulting copolymer morphology, particularly if the degree of polymerization (DP) of the PMAA stabilizer chains is longer than that of the PGMA. Two phase diagrams have been constructed to investigate the effect of the relative proportion and molar mass of the two macro-CTAs. Such a systematic approach is essential for the reproducible synthesis of pure worm-like micelles, which occupy relatively narrow phase space. The rheological behavior of a series of soft, free-standing worm gels is investigated. Finally, such gels are examined as model matrices for the growth of biomimetic calcite crystals and the role of the anionic PMAA stabilizer chains in directing crystal growth is evaluated.

\section{Introduction}

Polymerization-induced self-assembly (PISA) via reversible addition-fragmentation chain transfer (RAFT) dispersion polymerization $^{1-8}$ has been extensively investigated for the preparation of diblock copolymer nano-objects in aqueous, 4,9 14 alcoholic $^{7,15-19}$ or non-polar media., ${ }^{60-24}$ For example, RAFT aqueous dispersion polymerization has routinely been utilized for the synthesis of stimulus-responsive diblock copolymer nanoparticles comprising non-ionic poly(glycerol monomethacrylate) (PGMA) as a hydrophilic steric stabilizer and poly(2-hydroxypropyl methacrylate) (PHPMA) as the hydrophobic structure-directing block. ${ }^{4}$, 12, 13, 25-32 Recently, it has been reported that the presence of just one terminal carboxylic acid or morpholine group per PGMA chain confers pH-responsive behavior on PGMA-PHPMA worm-like micelles (herein denoted to as worms for brevity) or vesicles. ${ }^{28-31}$ Furthermore, the use of poly(methacrylic acid) (PMAA) as a neutral stabilizer block in ethanol allows the preparation of spheres, worms or vesicles simply by adjusting the mean degree

a. School of Materials, The University of Manchester, Oxford Road, Manchester, M13 9PL, UK. lee.fielding@manchester.ac.uk

b. Department of Materials Science and Engineering, Cornell University, Ithaca, NY 14853, USA.

Cold Regions Research and Engineering Laboratory (CRREL), US Army Corps of Engineers Engineer Research and Development Center, 72 Lyme Road, Hanover NH 03755, USA.

d. Department of Chemistry, The University of Sheffield, Brook Hill, Sheffield, South Yorkshire, S3 THF, UK.

Electronic Supplementary Information (ESI) available: [SAXS fitting parameters, SAXS model descriptions and variable temperature SAXS data]. See DOI: $10.1039 / x 0 x x 00000 x$ of polymerization (DP) of the hydrophobic poly(benzyl methacrylate) (PBzMA) block. ${ }^{33,34}$ However, targeting the same diblock copolymer compositions in aqueous media only leads to the formation of kinetically-trapped spheres owing to strong electrostatic repulsion between adjacent anionic stabilizer chains (owing to ionization of the methacrylic acid groups). ${ }^{35}$ Thus the use of anionic stabilizer blocks in RAFT aqueous dispersion polymerization formulations dramatically affects the self-assembly process and restricts the morphology of the block copolymer nanoparticles which can be obtained.

This problem was addressed by Semsarilar et al. for the synthesis of cationic nano-objects via RAFT aqueous dispersion polymerization using a quaternized poly(2(dimethylamino)ethyl methacrylate) macromolecular chain transfer agent (PQDMA macro-CTA) ${ }^{36}$ and also for the synthesis of anionic nano-objects prepared using a poly(potassium 3sulfopropyl methacrylate) (PKSPMA) macro-CTA. ${ }^{37}$ In particular, it was shown that the charge density within the coronal stabilizer layer could be reduced significantly by either (i) statistically copolymerizing the ionic monomer with a non-ionic GMA comonomer or (ii) using a binary mixture of ionic and nonionic macro-CTAs. The latter approach was recently extended by Williams et al. ${ }^{38}$ and Penfold et al. ${ }^{39,} 40$ who demonstrated that systematic variation of the mole fraction of the polyelectrolytic macro-CTA and the mean degrees of polymerization (DP) of the non-ionic, cationic and hydrophobic blocks enabled the reproducible formation of spheres, worms or vesicles. Overall, such studies indicate that using a binary mixture of macro-CTAs is a more flexible and less synthetically demanding approach than using statistical copolymer macroCTAs. 

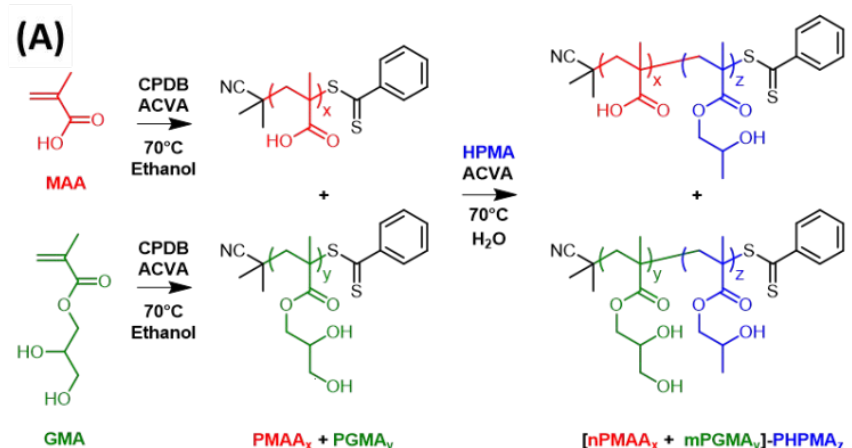

(B)
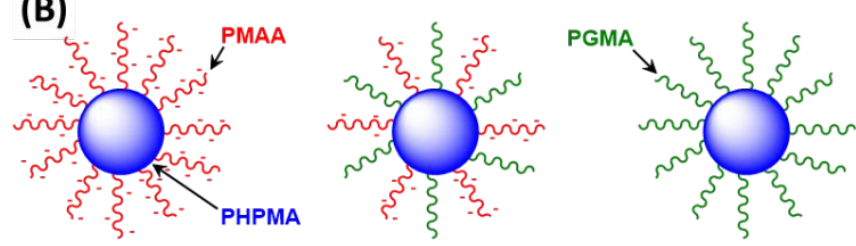

PMAA $_{x}-$ PHPMA $_{z}$

$\left[\mathrm{nPMAA}_{\mathrm{x}}+\mathrm{mPGMA}_{\mathrm{y}}\right]-\mathrm{PHPMA}_{\mathrm{z}}$

PGMA - -PHPMA

Figure 1. (A) Synthesis of $P M A A_{x}$ and $P G M A_{y}$ macro-CTAs via RAFT solution polymerization of either MAA or GMA in ethanol at $70^{\circ} \mathrm{C}$ using a dithiobenzoate-based RAFT agent. Binary mixtures of these two macro-CTAs are then used for the RAFT aqueous dispersion polymerization of HPMA at $70^{\circ} \mathrm{C}$ to produce diblock copolymer nanoobjects with tunable anionic surface character. (B) Schematic representation of PHPMA nanoparticles prepared using (i) PMAA $\mathrm{A}_{\mathrm{x}}$ macro-CTA alone; (ii) a binary mixture of PMAA and PGMA macro-CTAs (iii) PGMA $_{y}$ macro-CTA alone.

Herein, we utilize a binary mixture of macro-CTAs to prepare further examples of anionic diblock copolymer nano-objects directly in water. More specifically, anionic PMAA and non-ionic PGMA macro-CTAs with various DPs are prepared using the same dithiobenzoate-based RAFT agent and then pre-mixed prior to the RAFT aqueous dispersion polymerization of HPMA (Figure 1). This strategy provides access to a wide range of diblock copolymer nano-objects with tunable anionic character. Two scenarios are considered in this study: (i) the DP of the anionic PMAA stabilizer block exceeds that of the non-ionic PGMA block and (ii) the PMAA DP is less than that of the PGMA. In both cases, the copolymer morphologies obtained on systematic variation of the PMAA/PGMA molar ratio and the PHPMA DP are determined and phase diagrams are constructed. Aqueous electrophoresis studies are used to assess the anionic character of such nano-objects and the rheological behavior of a series of anionic worm gels is investigated. Furthermore, these worm gels are evaluated as model matrices for the growth of calcite crystals at $\mathrm{pH} 9$ and the role of the anionic carboxylate groups in the PMAA stabilizer chains in directing crystal growth is investigated.

\section{Experimental}

\section{Materials}

Glycerol monomethacrylate (GMA; 99.8\%) was donated by GEO Specialty Chemicals (Hythe, UK) and used without further purification. 2-Hydroxypropyl methacrylate (HPMA), methacrylic acid (MAA), 4,4'-azobis(4-cyanopentanoic acid) (ACVA), 2-cyano-2-propyldithiobenzoate (CPDB) and all other reagents were purchased from Sigma-Aldrich (UK) and were

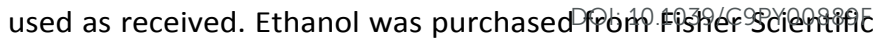
(UK), while $\mathrm{CD}_{3} \mathrm{OD}$ was purchased from Goss Scientific (UK). Deionized water was obtained from an in-house Elgastat Option 3 A water purification unit.

\section{Synthesis of poly(glycerol monomethacrylate) macro-chain transfer agent via RAFT solution polymerization}

The synthesis of PGMA macro-CTAs has been described in detail elsewhere. ${ }^{13}$ A typical synthesis of PGMA $_{62}$ macro-CTA was conducted as follows. A round-bottomed flask was charged with GMA (50 g; $312 \mathrm{mmol}$ ), CPDB (1.38 g; $6.2 \mathrm{mmol}$; target DP = 50), ACVA (350 mg, $1.2 \mathrm{mmol}$; CTA/initiator molar ratio $=5.0$ ) and ethanol (51.4 g). The sealed reaction vessel was purged with nitrogen and placed in a pre-heated oil bath at $70^{\circ} \mathrm{C}$ for $3 \mathrm{~h}$. The resulting PGMA (GMA conversion $=95 \% ; M_{n}=15,300 \mathrm{~g} \mathrm{~mol}^{-1}$, $M_{w} / M_{n}=1.15$ ) was purified by precipitation into excess dichloromethane. The mean degree of polymerization (DP) of this macro-CTA was calculated to be 62 by end-group analysis using ${ }^{1} \mathrm{H}$ NMR spectroscopy. ${ }^{13}$

Synthesis of poly(methacrylic acid) chain transfer agent via RAFT solution polymerization

The synthesis of PMAA macro-CTAs has been described in detail elsewhere. ${ }^{33}$ A typical synthesis of PMAA $_{85}$ macro-CTA was conducted as follows. A round-bottomed flask was charged with MAA (50 g; $581 \mathrm{mmol}$ ), CPDB (1.61 g; $7.3 \mathrm{mmol}$; target DP = 80), ACVA $(407 \mathrm{mg}, 1.5 \mathrm{mmol}$; CTA/initiator molar ratio $=5.0$ ) and ethanol $(77.4 \mathrm{~g})$. The sealed reaction vessel was purged with nitrogen and placed in a pre-heated oil bath at $70^{\circ} \mathrm{C}$ for $3 \mathrm{~h}$. The resulting PMAA (MAA conversion $=84 \% ; M_{n}=11,700 \mathrm{~g} \mathrm{~mol}^{-1}$, $M_{w} / M_{n}=1.12$ ) was purified by precipitation into excess diethyl ether. The mean DP of this macro-CTA was calculated to be 85 by end-group analysis using ${ }^{1} \mathrm{H} N \mathrm{NM}$ spectroscopy. ${ }^{33}$

Synthesis of [nPMAA + (1-n)PGMA ${ }_{y}$ ]-PHPMA ${ }_{z}$ diblock copolymer nano-objects via RAFT aqueous dispersion polymerization of HPMA

Binary mixtures of PMAA $A_{x}$ and $P G M A_{y}$ were used as macro-CTAs for the RAFT aqueous dispersion polymerization of HPMA in order to produce copolymer nanoparticles that are hereafter denoted as $\left[\mathrm{nPMAA}_{\mathrm{x}}+(1-\mathrm{n}) \mathrm{PGMA}\right.$ ] - PHPMA , where $n, x, y$ and $z$ are systematically varied. A typical RAFT aqueous dispersion polymerization synthesis of $\left[0.1 \mathrm{PMAA}_{37}+0.9 \mathrm{PGMA}_{68}\right]-$ PHPMA $_{100}$ at $20 \% \mathrm{w} / \mathrm{w}$ solids was conducted as follows. PGMA 68 macro-CTA (0.40 g; 36 mmol), PMAA 37 macro-CTA (14 mg; 4 $\mathrm{mmol}$ ) and ACVA initiator $(2.2 \mathrm{mg} ; 8 \mathrm{mmol}$; combined macro$\mathrm{CTA} /$ initiator molar ratio $=5.0$ ) were dissolved in water and the solution was adjusted to $\mathrm{pH} 5.2$ using dilute (0.01 or $0.1 \mathrm{M}$ ) sodium hydroxide solution (total volume added $=3.95 \mathrm{~mL}$ ). HPMA (0.574 g; 4 mmol; target DP = 100) was then added and the reaction mixture was sealed in a vial and purged with nitrogen gas for $15 \mathrm{~min}$. This deoxygenated solution was placed in a pre-heated oil bath at $70^{\circ} \mathrm{C}$ for $3 \mathrm{~h}(>99 \%$ final HPMA conversion; $\left.M_{n}=30,300 \mathrm{~g} \mathrm{~mol}^{-1}, M_{w} / M_{n}=1.15\right)$. In further syntheses, $n, x, y$ and $z$ were varied by adjusting the mean DP of each macro-CTA, the macro-CTA mol. \%, and the mass of HPMA monomer, under otherwise identical reaction conditions. 
$\left[\mathrm{nPMAA}_{\mathrm{x}}+\mathrm{mPGMA}_{\mathrm{y}}\right]-\mathrm{PHPMA}_{z}$
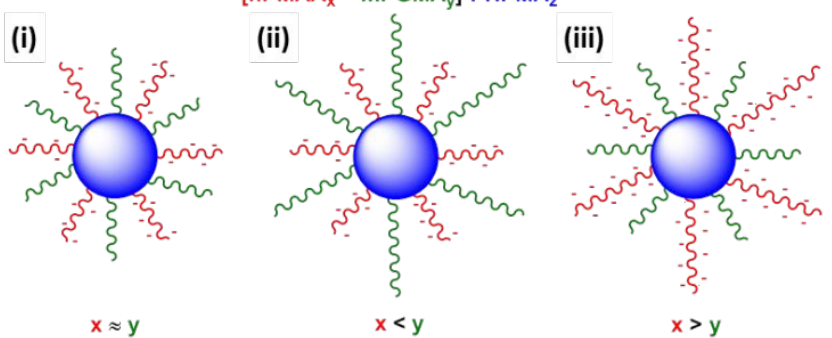

Figure 2. Schematic representation of three scenarios for $\mathrm{PHPMA}_{z}$-core nanoparticles prepared using binary mixtures of $\mathrm{PMAA}_{\mathrm{x}}$ and $\mathrm{PGMA}_{\mathrm{y}}$ stabilizer chains: (i) when the $\mathrm{PMAA}_{\mathrm{x}}$ and $P G M A_{y}$ DPs are comparable, (ii) when the PMAA $A_{x}$ DP is shorter than that of the PGMA $A_{y}$ block and (iii) when the $\mathrm{PMAA}_{x}$ is longer than that of the PGMA $\mathrm{A}_{y}$ block.

Table 1. Summary of $\mathrm{PMAA}_{x}$ and PGMA $\mathrm{A}_{y}$ macro-CTA compositions, monomer conversions, molar masses and dispersities

\begin{tabular}{|c|c|c|c|}
\hline $\begin{array}{c}\text { Polymer } \\
\text { composition }\end{array}$ & $\begin{array}{c}\text { Monomer } \\
\text { conversion } \\
\end{array}$ & $\begin{array}{c}\mathrm{M}_{\mathrm{n}}{ }^{a} \\
/ \%\end{array}$ & $\mathrm{M}_{\mathrm{w}} / \mathrm{M}_{\mathrm{n}}{ }^{b}$ \\
\hline $\mathrm{PMAA}_{37}$ & 68 & 9300 & 1.17 \\
\hline $\mathrm{PMAA}_{85}$ & 84 & 11700 & 1.12 \\
\hline $\mathrm{PGMA}_{48}$ & 56 & 13500 & 1.15 \\
\hline $\mathrm{PGMA}_{62}$ & 95 & 15300 & 1.15 \\
\hline $\mathrm{PGMA}_{68}$ & 82 & 15000 & 1.24 \\
\hline
\end{tabular}

${ }^{a}$ Determined by ${ }^{1} \mathrm{H}$ NMR spectroscopy. ${ }^{b}$ Determined by aqueous GPC using a

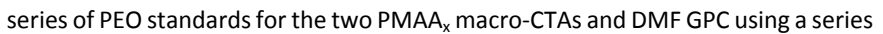
of poly(methyl methacrylate) standards for the three PGMA macro-CTAs

\section{Copolymer characterization}

Molar mass distributions for PGMA and the copolymers were assessed using a gel permeation chromatography (GPC) instrument equipped with a Varian 290-LC pump injection module, a Varian 390-LC refractive index detector, and two Polymer Laboratories PL gel $5 \mathrm{~mm}$ Mixed-C columns with a mobile phase of DMF at $60^{\circ} \mathrm{C}$ containing $0.01 \mathrm{M} \mathrm{LiBr}$ and a flow rate of $1.0 \mathrm{~mL} \mathrm{~min}{ }^{-1}$. DMSO was used as a flow-rate marker. Calibration was achieved using a series of poly(methyl methacrylate) standards. PMAA-containing diblock copolymers were methylated using trimethylsilyldiazomethane prior to analysis. ${ }^{41}$ Molar mass data for PMAA macro-CTAs were assessed using aqueous GPC analysis using an Agilent Technologies Infinity 1260 set-up equipped with a refractive index detector and two PL aquagel-OH $308 \mu \mathrm{m}$ columns running at $35{ }^{\circ} \mathrm{C}$. The $\mathrm{GPC}$ eluent comprised deionized water containing $30 \mathrm{vol}$. \% methanol at $\mathrm{pH} 9$ at a flow rate of $1.0 \mathrm{~mL}$ $\mathrm{min}^{-1}$. Calibration was achieved using a series of poly(ethylene oxide) standards.

${ }^{1} \mathrm{H}$ NMR spectra were recorded in $\mathrm{CD}_{3} \mathrm{OD}$ using a Bruker AV1$400 \mathrm{MHz}$ spectrometer with typically sixty-four scans being averaged per spectrum.

Dynamic light scattering (DLS) and aqueous electrophoresis studies were performed using a Zetasizer Nano-ZS instrument (Malvern Instruments, UK) at a fixed scattering angle of $173^{\circ}$. Copolymer dispersions were diluted with water prior to DLS studies at $25^{\circ} \mathrm{C}$. Aqueous electrophoresis measurements were performed in the presence of $10^{-3} \mathrm{M} \mathrm{KCl}$ and the solution $\mathrm{pH}$ was adjusted by addition of $0.01 \mathrm{M} \mathrm{HCl}$ or $0.01 \mathrm{M} \mathrm{KOH}$ using an autotitrator. Data were collected and analyzed using Dispersion Technology Software version 6.20. DOI: 10.1039/C9PY00889F Transmission electron microscopy (TEM) studies were conducted using a Philips CM 100 instrument operating at 100 $\mathrm{kV}$ and equipped with a Gatan $1 \mathrm{k}$ CCD camera. Diluted block copolymer solutions $(<0.50 \% \mathrm{w} / \mathrm{w})$ were placed on carboncoated copper grids and exposed to uranyl formate for 30 seconds at $20^{\circ} \mathrm{C}$ and dried under ambient conditions prior to analysis. This heavy metal compound acted as a negative stain to improve contrast.

Storage $\left(G^{\prime}\right)$ moduli as a function of \% strain were determined for copolymer worm gels using a TA Instruments AR-G2 rheometer equipped with a cone-and-plate geometry $(40 \mathrm{~mm}$ $2^{\circ}$ aluminum cone). Measurements were conducted at $0.1 \mathrm{rad}$ $\mathrm{s}^{-1}$ at $25^{\circ} \mathrm{C}$. Temperature sweep measurements were conducted using the same instrument at $0.1 \mathrm{rad} \mathrm{s}^{-1}$ and $0.1 \%$ strain. A thermal cycle of $25-2-25{ }^{\circ} \mathrm{C}$ was used, with all samples being equilibrated for $5 \mathrm{~min}$ prior to each temperature ramp. Thus, during these experiments, the gels were equilibrated at $25^{\circ} \mathrm{C}$ for $5 \mathrm{~min}$, cooled to $2^{\circ} \mathrm{C}$ at $2{ }^{\circ} \mathrm{C} \mathrm{min}-1$, equilibrated for $5 \mathrm{~min}$ and then heated back to $25^{\circ} \mathrm{C}$ at $2{ }^{\circ} \mathrm{C} \mathrm{min}-1$.

Small-angle X-ray scattering (SAXS) patterns for $1.0 \% \mathrm{w} / \mathrm{w}$ $\left[\mathrm{nPMAA}_{37}+\mathrm{mPGMA}_{68}\right]-\mathrm{PHPMA}_{\mathrm{z}}$ dispersions were collected at ESRF (Grenoble, France), station BM26, using monochromatic $X$-ray radiation and a $2 \mathrm{D}$ Pilatus $1 \mathrm{M}$ CCD detector. Glass capillaries of $2 \mathrm{~mm}$ diameter were used as a sample holder and scattering data were reduced by Nika SAS macros for Igor Pro (integration and normalization). ${ }^{42}$ SAXS patterns for $1.0 \% \mathrm{w} / \mathrm{w}$ $\left[\mathrm{nPMAA}_{85}+(1-n) \mathrm{PGMA}_{62}\right]-\mathrm{PHPMA}_{z}$ dispersions and $5.0 \% \mathrm{w} / \mathrm{w}$ $\left[\mathrm{nPMAA}_{85}+(1-n) \mathrm{PGMA}_{48}\right]-\mathrm{PHPMA}_{140}$ worm gels were acquired at Diamond Light Source (Didcot, UK), station 122, using monochromatic X-ray radiation and a 2D Pilatus $2 \mathrm{M}$ pixel detector. A polycarbonate or glass capillary cell of $2 \mathrm{~mm}$ diameter was used as a sample holder and temperature control was achieved using a heating/cooling sample holder (Linkam Scientific Instruments Ltd, Tadworth, England). 2D scattering data were reduced to 1D patterns using Dawn software developed at the Diamond Light Source. All SAXS data were further analyzed (background subtracted and fitted) using Irena SAS macros for Igor Pro (see ESI). ${ }^{42}$

\section{Crystallization studies}

Crystal growth studies were performed as follows. $10 \mathrm{mM} \mathrm{CaCl}$ was added to the non-gelled copolymer solution at $2{ }^{\circ} \mathrm{C}$ to ensure thorough mixing. The resulting mixture was then allowed to warm up to ambient temperature. This led to regelation via a sphere-to-worm transition and the resulting aqueous worm gel was then placed within a desiccator. Solid ammonium carbonate was placed on a Petri dish in the desiccator to act as the carbonate source and crystals were grown at $20{ }^{\circ} \mathrm{C}$ for $48 \mathrm{~h}$. The gels were washed with methanol to remove the surrounding worm gel matrix and crystals were deposited onto glass slides. These slides were then mounted on aluminum stubs for SEM imaging and coated with $\sim 100 \mathrm{~nm}$ of a conductive carbon film to prevent sample charging before being imaged using a Tescan MIRA3 FESEM instrument. 

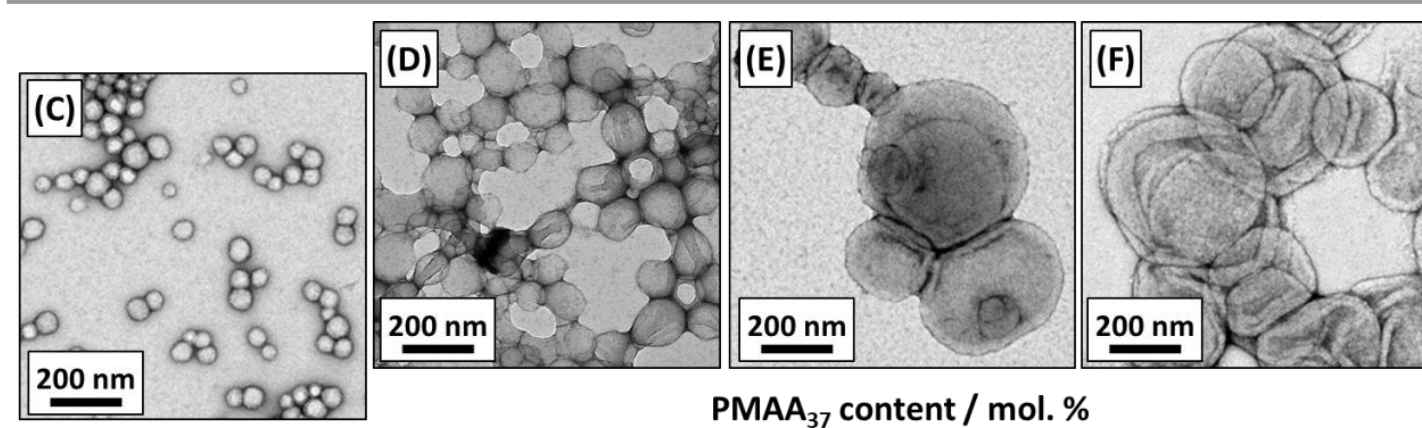

DOI: 10.1039/C9PY00889F
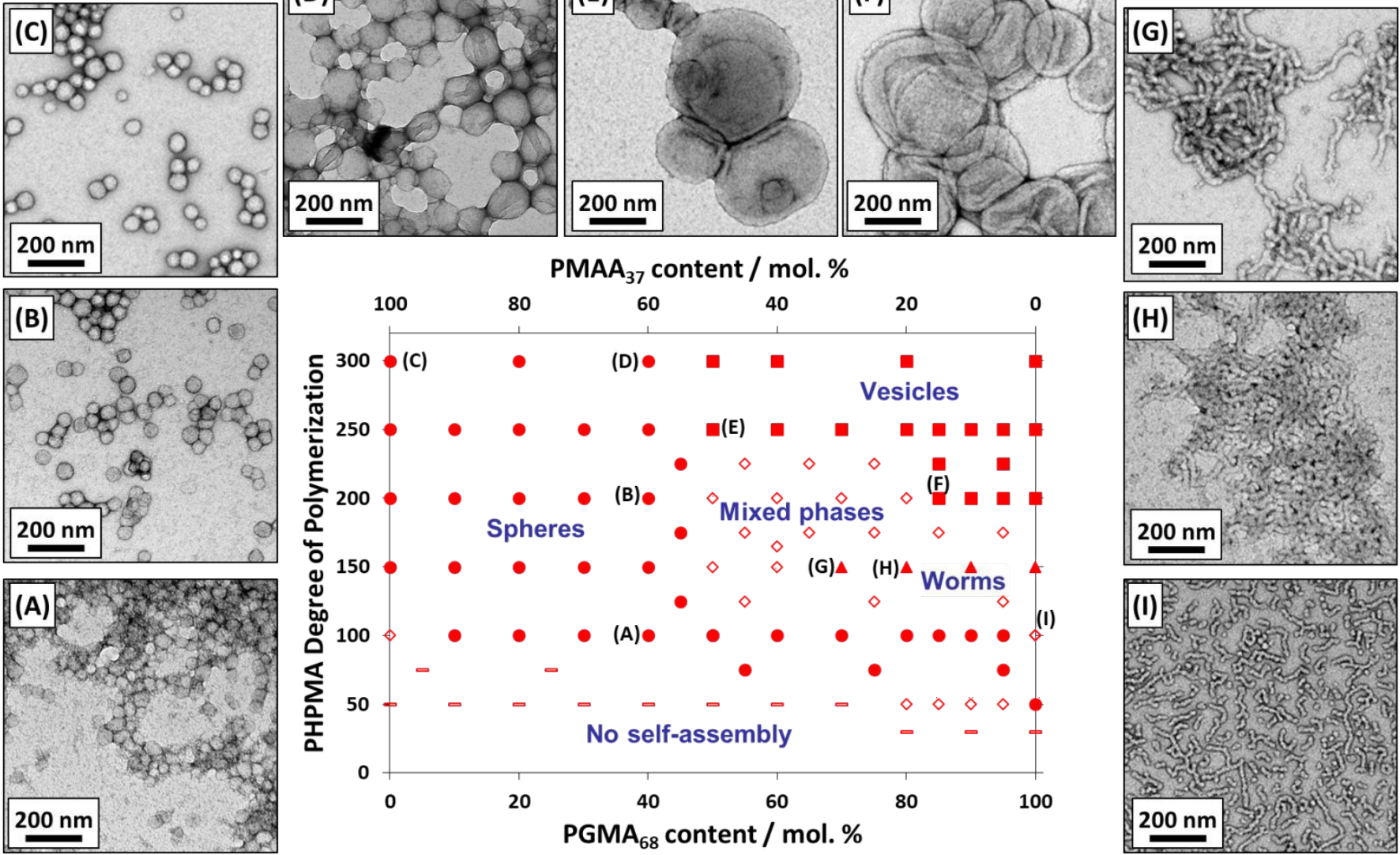

Figure 3. Phase diagram constructed for $\left[\mathrm{nPMAA}_{37}+\mathrm{mPGMA}_{68}\right]-\mathrm{PHPMA}$ diblock copolymer nanoparticles prepared by RAFT dispersion polymerization of $\mathrm{HPMA}$ in water at $20 \%$ $\mathrm{w} / \mathrm{w}$ solids using $\mathrm{ACVA}$ at $70^{\circ} \mathrm{C}$ (overall macro-CTA/ACVA molar ratio $=5.0$ ). Copolymer morphologies were assigned by TEM, with selected images corresponding to points labelled A to I shown on the phase diagram. Pure sphere, worm and vesicle phases are represented by circles, triangles and squares, respectively. Mixed phases are represented as hollow diamonds.

\section{Results and Discussion}

In principle, the judicious use of a binary mixture of macro-CTAs can offer a highly versatile approach for the rational design of charged diblock copolymer nanoparticles directly in water. ${ }^{36,37}$ This is because inclusion of a non-ionic stabilizer significantly reduces the mutual electrostatic repulsion between the polyelectrolytic stabilizer chains, which in turn facilitates in situ self-assembly. In the present study, an anionic $\mathrm{PMAA}_{\mathrm{x}}$ and a

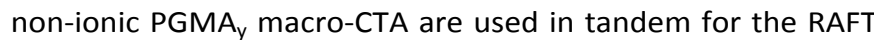
aqueous dispersion polymerization of HPMA to produce a series of $\left[\mathrm{nPMAA}_{\mathrm{x}}+(1-n) \mathrm{PGMA}_{\mathrm{y}}\right]-\mathrm{PHPMA}_{z}$ diblock copolymer nanoparticles of tunable anionic character and copolymer morphology by systematically varying the $n, x, y$ and $z$ parameters (see Figure 1). [N.B. For brevity, the shorthand notation $\left[\mathrm{nM}_{\mathrm{x}}+(1-n) \mathrm{G}_{\mathrm{y}}\right]-\mathrm{H}_{\mathrm{z}}$, is used for some of the Figures in this paper].

For a given PHPMA DP and a constant $\mathrm{PMAA}_{\mathrm{x}} / \mathrm{PGMA}_{\mathrm{y}}$ molar ratio, there are three possible regimes: (i) when the $P M A A_{x} D P$ is comparable to that of $P G M A_{y}$, (ii) when the $P M A A_{x}$ block is shorter than the $P G M A_{y}$ block and (iii) when the $P M A A_{x} D P$ exceeds that of $\mathrm{PGMA}_{y}$ (see Figure 2 ). The self-assembly behavior observed for scenario (i) is expected to lie between that of scenarios (ii) and (iii). Therefore we chose to focus on the latter two scenarios. In each case the $\mathrm{PMAA}_{\mathrm{x}} / \mathrm{PGMA}_{\mathrm{y}}$ molar ratio and $\mathrm{PHPMA}_{z} \mathrm{DP}$ are systematically varied to examine the impact of using dissimilar macro-CTA DPs for PISA syntheses.

Synthesis of poly(methacrylic acid) and poly(glycerol monomethacrylate) macro-CTAs

The RAFT solution polymerization of either GMA or MAA was conducted in ethanol at $70^{\circ} \mathrm{C}$. Such syntheses afforded five lowdispersity macro-CTAs $\left(M_{w} / M_{n}<1.25\right)$ with the following compositions: $\mathrm{PMAA}_{37}, \mathrm{PMAA}_{85}, \mathrm{PGMA}_{48}, \mathrm{PGMA}_{62}$ and PGMA 68 (see Table 1). Each polymerization was quenched at between 56 and $95 \%$ conversion in order to avoid monomer-starved conditions and hence ensure retention of the RAFT endgroups. ${ }^{43}$ This precaution is usually considered a prerequisite for high blocking efficiencies and hence well-defined diblock copolymers. These macro-CTAs were used in various binary combinations for the RAFT aqueous dispersion polymerization of HPMA so as to prepare a series of diblock copolymer nanoparticles via PISA.

\section{Block Copolymer Synthesis}

In all cases, the two macro-CTAs were mixed as dry powders prior to dissolution in water and addition of HPMA monomer. A series of copolymers were prepared whereby the DP and molar ratio of each macro-CTA (steric stabilizer) were varied, along 


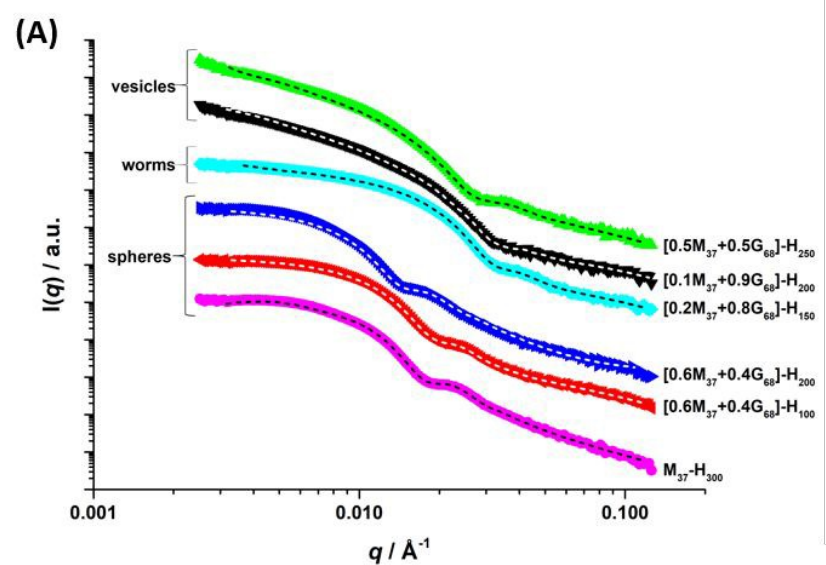

(B)

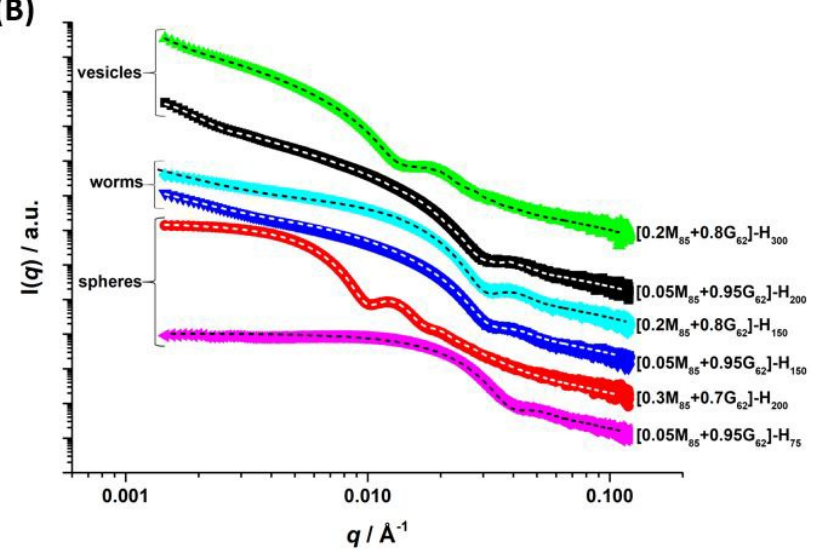

Figure 4. Small angle $X$-ray scattering (SAXS) patterns and data fits (dashed lines) recorded for $1.0 \% \mathrm{w} / \mathrm{w}$ dispersions of $(\mathrm{A})\left[\mathrm{nPMAA}_{37}+\mathrm{mPGMA}_{68}\right]-\mathrm{PHPMA}_{2}$ and $(\mathrm{B})$ $\left[\mathrm{nPMAA}_{85}+(1-\mathrm{n}) \mathrm{PGMA}_{62}\right]-\mathrm{PHPMA}_{z}$ diblock copolymer nanoparticles synthesized via RAFT dispersion polymerization of HPMA in water at $20 \% \mathrm{w} / \mathrm{w}$ solids using ACVA at $70^{\circ} \mathrm{C}$.

with the DP of the PHPMA core-forming block, overall copolymer concentration and $\mathrm{pH}$ of the aqueous phase. In principle, each of these parameters can affect the copolymer morphology obtained via PISA. In order to reduce the number of variables, all polymerizations were conducted targeting an overall copolymer concentration of $20 \% \mathrm{w} / \mathrm{w}$ at $\mathrm{pH} 5.2 .{ }^{34}$ This $\mathrm{pH}$ was chosen as it lies close to the $\mathrm{pK}_{\mathrm{a}}$ of the PMAA chains. This ensures that this macro-CTA is soluble but not fully ionized, hence conferring significant (but not maximum) anionic character. Finally, it is well-known that the RAFT chain-ends are susceptible to hydrolytic degradation above neutral $\mathrm{pH}^{, 4}$ hence such conditions were avoided. A copolymer concentration of 20 $\% \mathrm{w} / \mathrm{w}$ was chosen as this allows direct comparison with much of the prior PISA literature on the PGMA-PHPMA formulation previously reported by Armes and co-workers, with such conditions enabling convenient access to worms and vesicles as well as spheres. ${ }^{4}$ Each of these PISA syntheses attained more than $99 \%$ HPMA conversion within $3 \mathrm{~h}$ at $70^{\circ} \mathrm{C}$ hence copolymer dispersions were not purified further prior to analysis.

\section{Case 1: Short anionic block (PMAA 37 Vs. PGMA 68 )}

Initially, we examined a binary mixture of a relatively short anionic $\mathrm{PMAA}_{37}$ stabilizer with a non-ionic PGMA 68 stabilizer. This combination was expected to minimize mutual electrostatic repulsion between the $\mathrm{PMAA}_{37}$ stabilizer chains

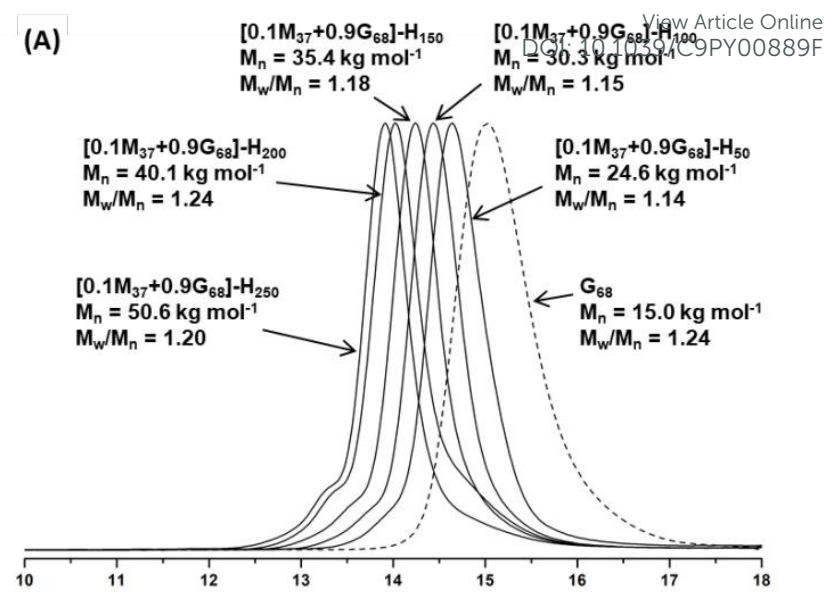

(B)

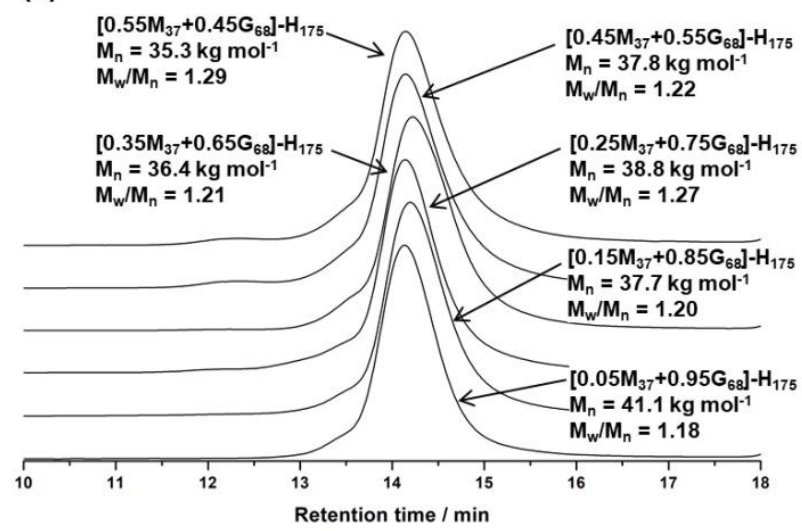

Figure 5. $D M F$ gel permeation chromatograms (refractive index detector) obtained for $\left[\mathrm{nPMAA}_{37}+(1-n) \mathrm{PGMA}_{68}\right.$ ]-PHPMA for which $(\mathrm{A}) \mathrm{n}$ is fixed at 0.1 and $\mathrm{z}$ is varied from 0 to 250; (B) $n$ is varied from 0.05 to 0.55 and $z$ is fixed at 175 . In each case calibration was achieved using a series of poly(methyl methacrylate) standards.

but perhaps also reduce the overall surface charge on the resulting nano-objects.

A phase diagram was constructed in which the PHPMA coreforming block DP is plotted against the PGMA ${ }_{68}$ (or PMAA ${ }_{37}$ ) content expressed in mol. \% (Figure 3 ). The morphologies of the resulting copolymer nano-objects were initially assigned by extensive TEM studies. However, given their apparent deformability and relatively high polydispersity, some 'spheres' labelled on this phase diagram could be potentially assigned as vesicles. Particular uncertainty arises when examining data points lying close to phase boundaries (e.g. Point D in Figure 3). Thus selected morphology assignments were verified by SAXS analysis using previously reported models and protocols ${ }^{23,32,45-}$ 48 (see Figure 4A and ESI). When the PGMA 68 macro-CTA was used as the sole steric stabilizer, copolymer morphologies ranged from spheres to worms to vesicles, as expected (Figure 3). Moreover, the DP of the PHPMA block required to access each morphology agrees rather well with the phase diagram previously reported for the previously reported $\mathrm{PGMA}_{78^{-}}$ $\mathrm{PHPMA}_{z}$ system. ${ }^{25}$ In contrast, self-assembly requires a much higher PHPMA DP $(>100)$ when using the PMAA $_{37}$ macro-CTA as the sole steric stabilizer. Moreover, in this case the final copolymer morphology is confined to kinetically-trapped 

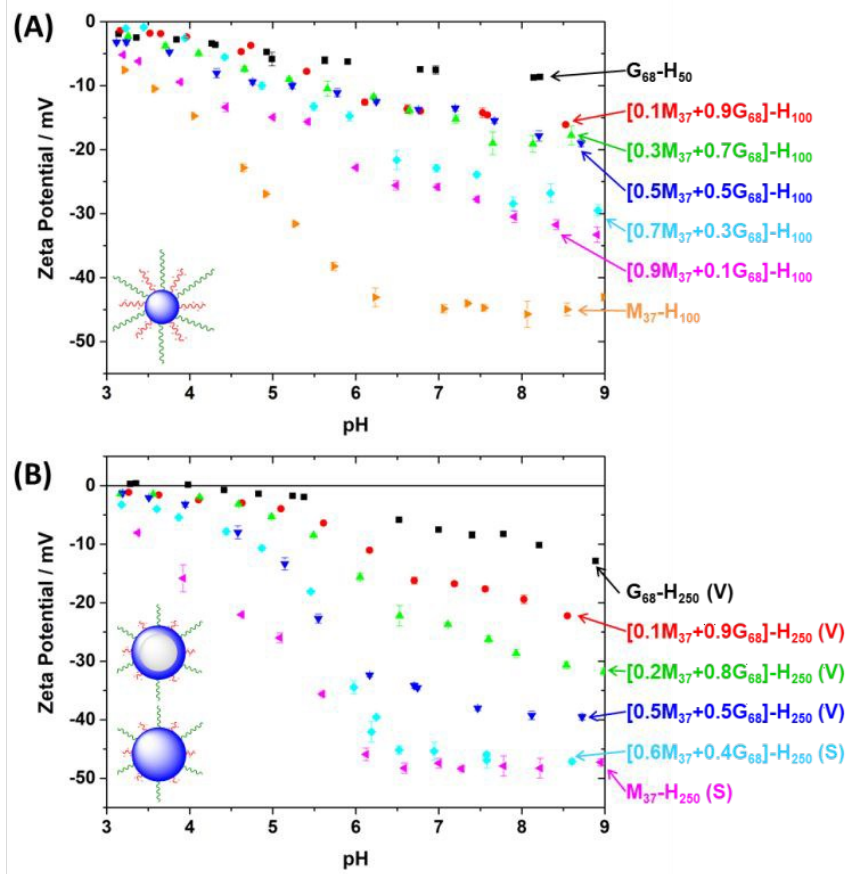

Figure 6. Zeta potential versus $\mathrm{pH}$ curves recorded for $(A)\left[\mathrm{nPMAA}_{37}+(1-n) \mathrm{PGMA}_{68}\right]$ $\mathrm{PHPMA}_{50-100}$ spheres and (B) $\left[n \mathrm{PMAA}_{37}+(1-n) \mathrm{PMAA}_{68}\right]-\mathrm{PHPMA}_{250}$ spheres $(\mathrm{S})$ or vesicles (V).

spheres with mean diameters of $\sim 50-150 \mathrm{~nm}$. This is because mutual electrostatic repulsion is sufficiently strong to prevent sphere-sphere fusion, which is the essential first step for worm formation. ${ }^{4}, 32$ This restriction in morphology is also observed for all binary mixtures of macro-CTAs down to $50 \mathrm{~mol}$. \% $\mathrm{PMAA}_{37}$, confirming that the presence of polyelectrolytic stabilizer chains significantly impedes block copolymer selfassembly in aqueous solution. However, the phase diagram becomes more interesting for lower $\mathrm{PMAA}_{37}$ contents (i.e. 5-50 mol. \%). There is a large mixed phase region surrounding a rather narrow worm phase, while pure vesicles can be prepared when targeting PHPMA DPs of 200-300 (with a lower PMAA 37 content favoring vesicle formation at a lower PHPMA DP). In general, these observations are consistent with various phase diagrams that have been constructed for related PISA formulations. ${ }^{14,} 25,46,49,50$

In order to confirm that both macro-CTAs were chain-extended during the RAFT dispersion polymerization of HPMA, selected samples were analyzed by gel permeation chromatography (GPC) using DMF eluent, with exhaustive methylation of the anionic carboxylate groups ensuring minimal adverse interactions with the GPC columns. Figure $5 \mathrm{~A}$ shows molar mass distributions obtained for a series of samples prepared at a fixed $\mathrm{PGMA}_{68}$ content of $90 \mathrm{~mol}$. \% while systematically increasing the PHPMA DP. As expected, these distributions gradually shift to lower retention times while remaining relatively narrow. There is minimal contamination by $\mathrm{PMAA}_{37}$ or $\mathrm{PGMA}_{68}$ macroCTA in these chromatograms (a low molar mass shoulder is observed in one case), while the high molar mass feature previously assigned to light branching ${ }^{12}$ remains weak in all cases. Figure 5B shows a series of overlaid GPC traces where
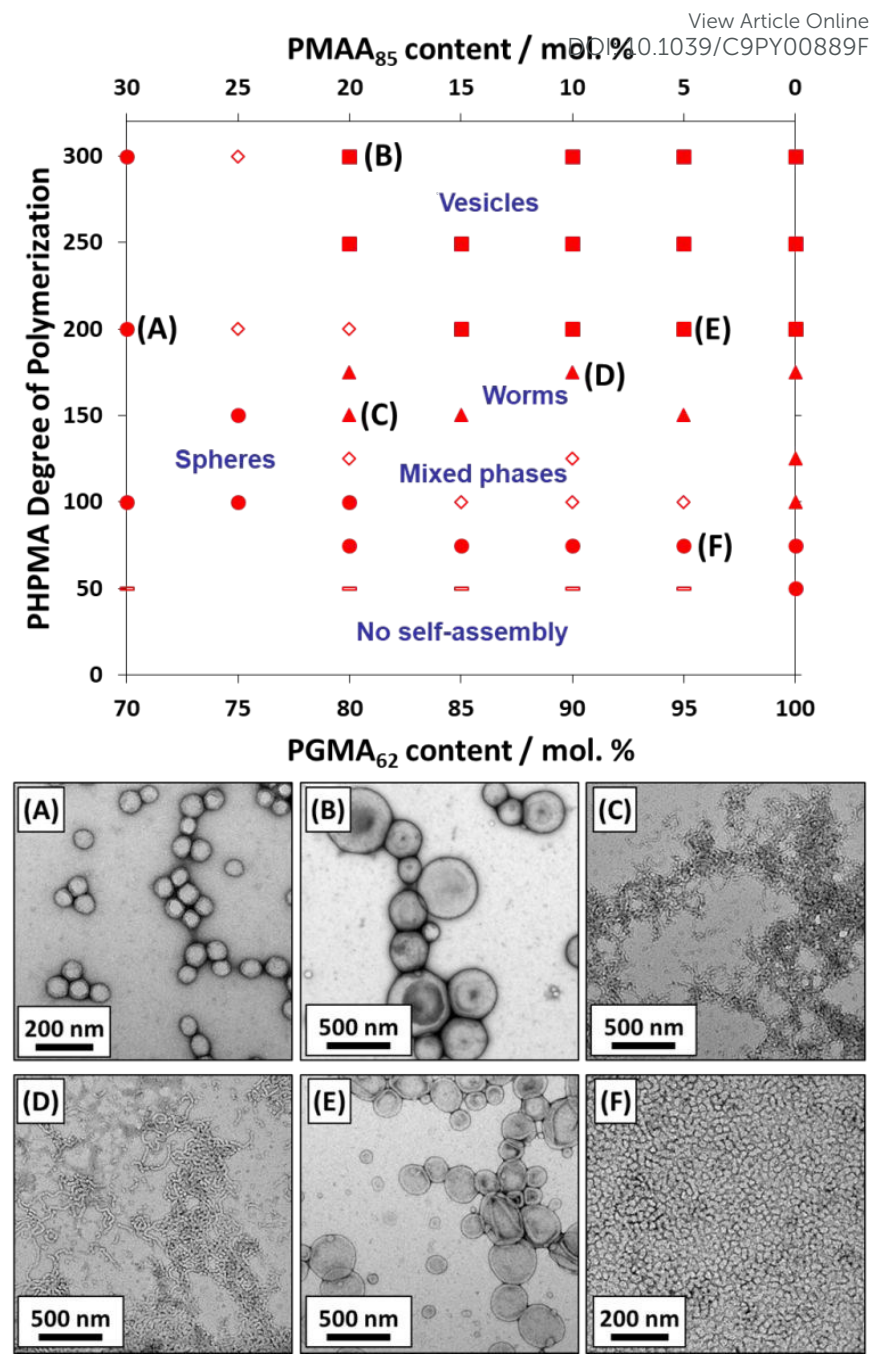

Figure 7. Phase diagram constructed for $\left[n \mathrm{PMAA}_{85}+(1-n) \mathrm{PGMA}_{62}\right]-\mathrm{PHPMA}_{z}$ diblock copolymer nanoparticles prepared by RAFT dispersion polymerization of HPMA in water at $20 \% \mathrm{w} / \mathrm{w}$ solids using ACVA at $70^{\circ} \mathrm{C}$ (overall macro-CTA/ACVA molar ratio $=5.0$ ). Pure sphere, worm and vesicle phases are represented by circles, triangles and squares, respectively. Mixed phases are represented as hollow diamonds. Copolymer morphologies were assigned by TEM, with selected images corresponding to points labeled $\mathrm{A}$ to $\mathrm{F}$ on the phase diagram.

the target PHPMA DP is fixed at 175 and the $\mathrm{PMAA}_{37}$ content is systematically varied from 5 to $55 \mathrm{~mol}$. \%. As expected, the peaks overlap well and the $M_{n}$ values are relatively consistent. However, higher PMAA contents tend to correlate with slightly higher dispersities. This may indicate some residual anionic carboxylate groups remaining after methylation causing weak interactions with the GPC columns. Nevertheless, these GPC data suggest that both macro-CTAs are chain-extended during PISA syntheses.

Aqueous electrophoresis measurements were performed on two series of copolymer nano-objects as a function of $\mathrm{pH}$. Figure $6 \mathrm{~A}$ shows a series of zeta potential vs. $\mathrm{pH}$ curves recorded for a range of kinetically-trapped spheres of varying $\mathrm{PMAA}_{37}$ content while targeting a PHPMA DP of either 50 or 100. Similarly, Figure $6 \mathrm{~B}$ shows a series of zeta potential vs. $\mathrm{pH}$ curves recorded for nano-objects prepared at a fixed PHPMA DP of 250 (vesicles 


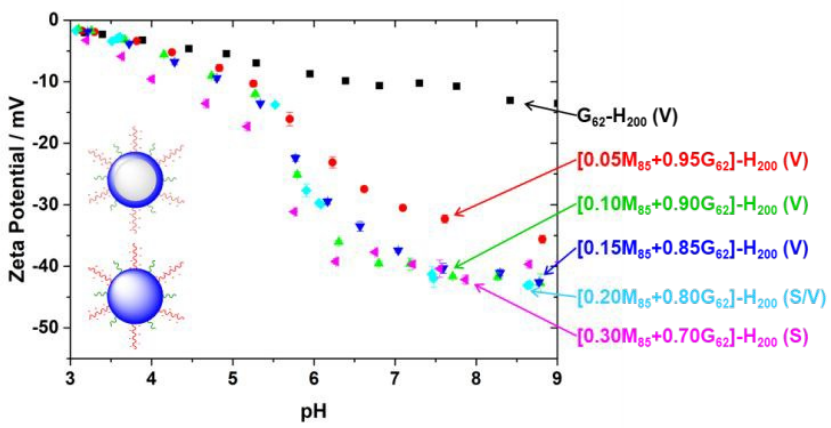

Figure 8. Zeta potential versus $\mathrm{pH}$ curves recorded for selected $\left[\mathrm{nPMAA}_{85}+(1-\right.$ n)PGMA ${ }_{62}$ ]-PHPMA 200 vesicles (V) and spheres (S).

when using less than 50 mol. \% $\mathrm{PMAA}_{37}$, spheres when using 50 mol. \% $\mathrm{PMAA}_{37}$ or higher). In all cases, copolymer nano-objects containing $\mathrm{PMAA}_{37}$ stabilizer chains exhibit negative zeta potentials across the entire $\mathrm{pH}$ range. Moreover, zeta potentials become significantly more negative above $\mathrm{pH} 4.5$ before reaching a plateau value above $\mathrm{pH} \sim 8$. Interestingly, it is apparent that nanoparticles with a longer PHPMA DP (Figure $6 \mathrm{~B})$ display more negative zeta potentials than those with shorter DPs (Figure 6A). This is the case even for nanoparticles that contain lower PMAA contents. A similar effect has been previously reported for sulfate-based nanoparticles comprising varying surface densities of anionic stabilizer chains. ${ }^{51}$ Thus the zeta potential data observed herein may indicate differing relative surface stabilizer densities owing to variation in particle diameter and/or aggregation number. It is also clear that nanoobjects containing a higher proportion of $\mathrm{PMAA}_{37}$ possess much more anionic character. Thus, judicious selection of the $\mathrm{PMAA}_{37}$ content provides rather fine control over their electrophoretic behavior, as well as the copolymer morphology.

\section{Case 2: Long anionic block (PMAA 85 Vs. PGMA 6 )}

In these series of experiments, binary mixtures of PGMA 62 and $\mathrm{PMAA}_{85}$ macro-CTAs were used for the RAFT aqueous dispersion polymerisation of HPMA. In this case, the relatively long anionic $\mathrm{PMAA}_{85}$ block was expected to exert a greater influence over self-assembly and/or the electrophoretic behavior of the nano-objects.

Figure 7 depicts the relevant phase diagram and associated TEM images for this second set of PISA syntheses, with post mortem SAXS analysis confirming assignment of the appropriate copolymer morphologies (Figure 4B). Again, using the non-ionic $\mathrm{PGMA}_{62}$ macro-CTA alone produces spheres, worms and vesicles, depending on the target PHPMA DP. In contrast, using $\mathrm{PMAA}_{85}$ alone (or $\mathrm{PMAA}_{85}$-rich compositions) only provides access to kinetically-trapped spheres. However, it is emphasized that worms or vesicles can now only be obtained at $\mathrm{PMAA}_{85}$ contents up to $\sim 25 \mathrm{~mol}$. \%. Hence the entire phase diagram is essentially shifted to the right when compared to Figure 3. These observations corroborate our hypothesis that longer anionic stabilizer chains should disrupt self-assembly to a greater extent than relatively short stabilizers under otherwise identical conditions.

Figure 8 shows the aqueous electrophoresis data obtained for selected nano-objects within this series, for which the target

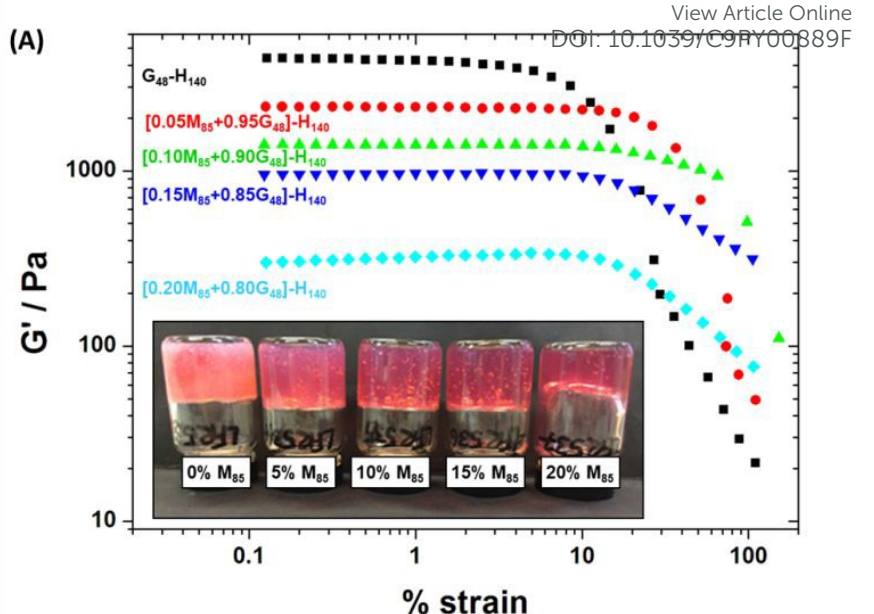

(B)
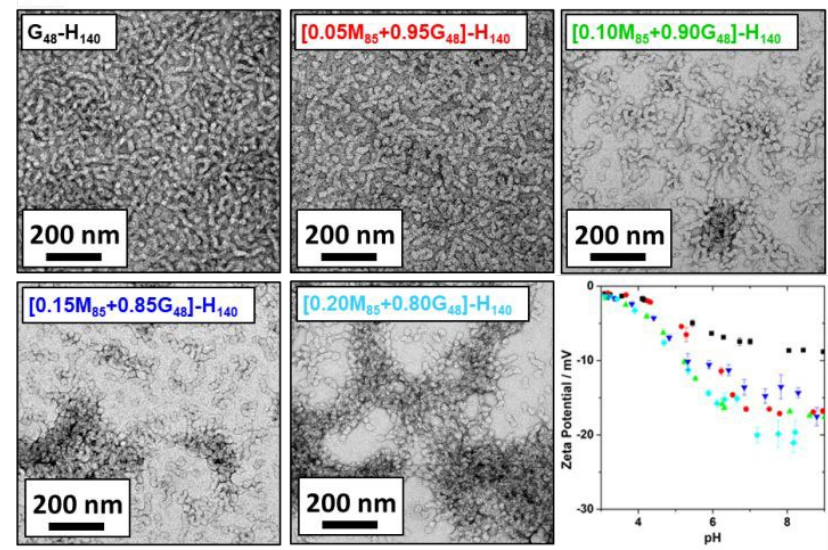

Figure 9. (A) Storage modulus ( $G^{\prime}$ ) versus \% strain curves obtained by rheological studies of a series of five $20 \% \mathrm{w} / \mathrm{w}$ worm gels. All measurements were conducted at $0.1 \mathrm{rad} \mathrm{s}^{-1}$ at $25{ }^{\circ} \mathrm{C}$ using a cone-and-plate geometry. The inset digital photograph shows inverted vials containing these five worm gels, demonstrating their free-standing nature. (B) TEM images and aqueous electrophoresis versus $\mathrm{pH}$ curves of highly diluted $(\sim 0.05 \% \mathrm{w} / \mathrm{w})$ worm gels.

PHPMA DP was fixed at 200. Zeta potentials remain negative throughout the $\mathrm{pH}$ range investigated and become relatively constant above approximately $\mathrm{pH}$ 8. However, for this series there is rather little scope for tuning the electrophoretic behavior. Thus, the zeta potential for a binary mixture containing just 5 mol. \% $\mathrm{PMAA}_{85}$ is $-35 \mathrm{mV}$ at $\mathrm{pH}$ 9, which is close to that observed when using $\geq 10$ mol. \% $\operatorname{PMAA}_{85}(\sim-40 \mathrm{mV})$. Clearly, the relatively long $\mathrm{PMAA}_{85}$ stabilizer chains extend further away from the surface of the nanoparticles than the shorter non-ionic $\mathrm{PGMA}_{62}$ stabilizer chains. Thus the electrophoretic behavior is more strongly influenced by the anionic charge on the former chains than in case 1 above, where they are presumably 'buried' to some extent within a relatively thick PGMA corona.

\section{Growth of calcium carbonate crystals within worm gels}

In principle, this new class of model anionic nanoparticles, which exhibit precisely controlled size (for spheres), adjustable morphology and tunable anionic surface character (particularly for case 1), should provide new insights for biomineralization studies. ${ }^{50,52-59}$ For example, an extensive study of the occlusion of the spherical micelles discussed in case 1 and 2 above within 

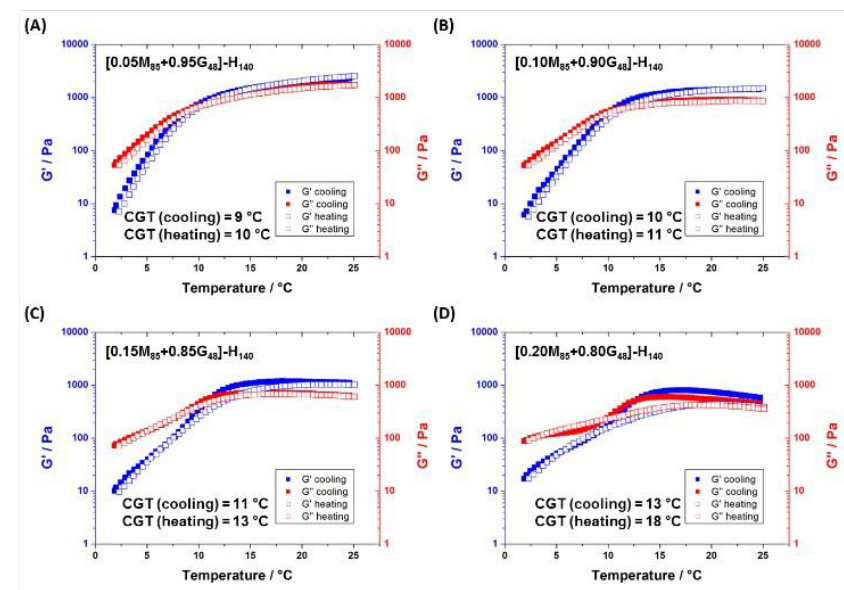

Figure 10. Storage modulus $\left(G^{\prime}\right)$ and loss modulus $\left(G^{\prime \prime}\right)$ versus temperature curves obtained by rheological studies of a series of $20 \% \mathrm{w} / \mathrm{w}$ worm gels of varying composition. All measurements were conducted at $0.1 \mathrm{rad} \mathrm{s}^{-1}$ and $0.1 \%$ strain using a cone-and-plate geometry. Each gel was subjected to a $25-2-25^{\circ} \mathrm{C}$ thermal cycle at cooling/heating rates of at $2{ }^{\circ} \mathrm{C} \mathrm{min}-1$ and equilibrated for 5 min at $2{ }^{\circ} \mathrm{C}$ before measurement to eliminate any thermal history.

calcite crystals has recently been reported by Kim and coworkers. ${ }^{59}$ It was found that nanoparticle occlusion was strongly influenced by both the overall anionic character and also the accessibility of the carboxylate groups located within the stabilizer chains. Nanoparticles comprising mixed PMAA/PGMA stabilizers were incorporated more effectively than those prepared using solely PMAA as a stabilizer. Moreover, lower activity was observed for the nanoparticles reported in case 1 above, when the anionic carboxylate groups are located well within the stabilizer layer. The strategy reported herein is to design new model nanoparticles in order to better understand occlusion phenomena; this approach is further illustrated with the following preliminary data.

Notably, both types of PISA formulations (i.e. case 1 and case 2) allow preparation of anionic block copolymer worms that form soft, free-standing hydrogels at ambient temperature. The phase space for this particular morphology is admittedly remarkably narrow but the phase diagrams shown in Figures 3 and 7 are sufficiently detailed to ensure that such PISA syntheses are highly reproducible. Moreover, the likely behavior for related macro-CTA combinations can be predicted with some confidence.

Hydrogels have been utilized for many applications, ranging from soft contact lenses ${ }^{60,61}$ to 3D cell culture ${ }^{62,63}$ to forming scaffolds for tissue engineering ${ }^{64,65}$ and to control of crystal growth. ${ }^{66-69}$ For example, for many of the organisms that utilize biomineralization, it has been demonstrated that this process occurs within a gel-like matrix, which is typically composed of a combination of polypeptides and/or polysaccharides.67-69 However, when selecting suitable gels based on such naturallyoccurring materials for bio-inspired studies, unacceptably large batch-to-batch variations in gel properties are often observed. Moreover, Nature often uses charged polypeptides whereas neutral agarose-based gels are commonly used for cell culture and synthetic crystal growth studies. For example, in an earlier study aimed at modeling biomineralization in mollusks (which

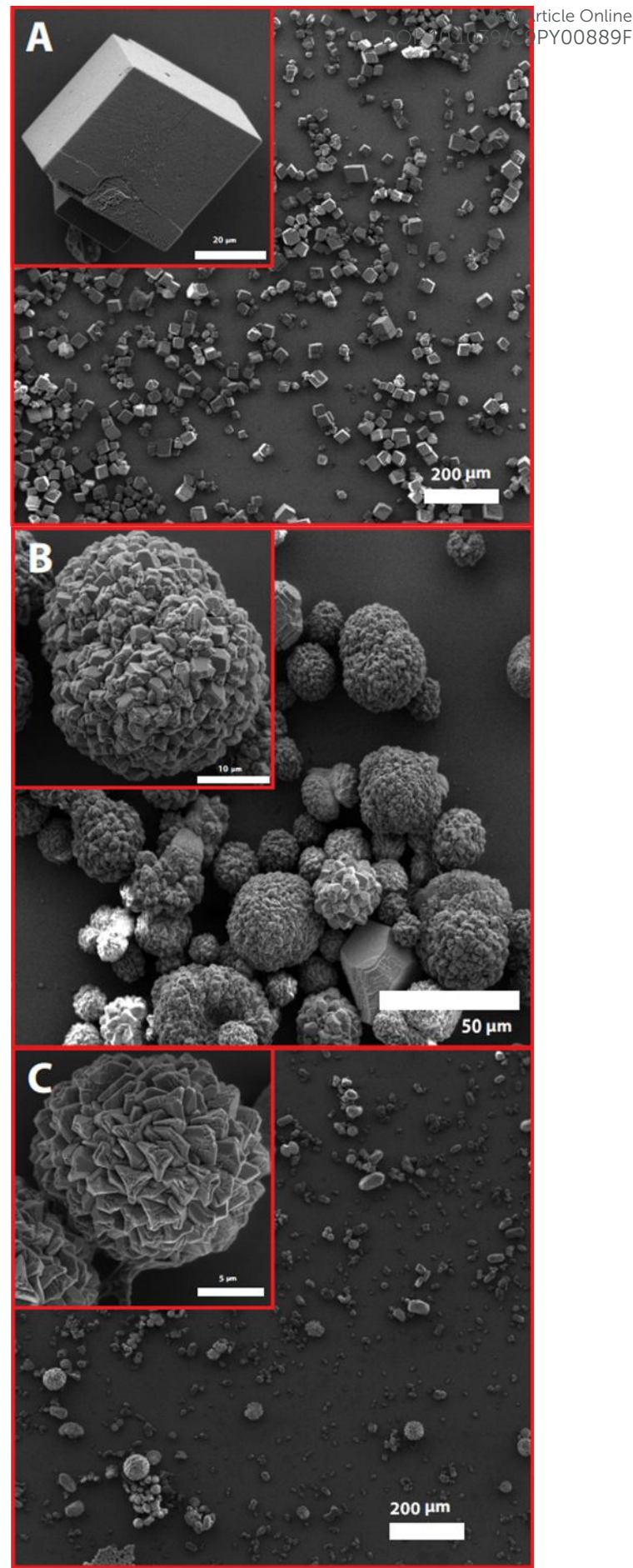

Figure 11. SEM images obtained for calcite crystals grown in the presence of [nPMAA $+(1-n) P_{\text {PMA }}$ ] -PHPMA ${ }_{140}$ worm gels where $\mathrm{n}=0,0.05$ and 0.15 for images $\mathrm{A}, \mathrm{B}$ and $\mathrm{C}$, respectively. Each gel was thoroughly washed with methanol prior to analysis in order to remove the surrounding worm gel matrix. Note the significant change in calcite morphology observed for crystals grown in a non-ionic worm gel $(A)$ and within two anionic worm gels (B, C).

grow calcite within an extensive organic matrix), large calcite single crystals were grown within an agarose gel. ${ }^{68}$ This neutral matrix had minimal chemical interaction with the growing crystals, allowing a focus on the physical aspects of crystallization in gels. To more closely model biological gel 
environments, we require gels that more closely resemble the natural biological matrix in terms of both chemical functionality and anionic surface charge in the gel environment. As demonstrated above, PISA allows the preparation of suitable anionic worm gels with highly reproducible chemical structures, adjustable gel strengths and tunable surface charge (or carboxylic acid content). Moreover, block copolymer nanoparticles have already provided substantial insights into how calcite grows in the presence of various additives. ${ }^{50-52,54,56}$ ${ }^{70}$ Thus we envisage that judicious use of the anionic worm gels prepared herein as crystallization matrices could provide insight into the roles of chemical variables with a gel environment in modifying crystal morphology and composition. Furthermore, the thermoreversible (de)gelation behavior of PHPMA-based worm gels, caused by a worm-to-sphere transition at low temperature, is well known. ${ }^{26,28,46,71}$ It was therefore expected that the anionic worm gels described herein would display the same thermoresponsive behavior and thus facilitate intimate mixing with cold crystal growth solution prior to gel reformation and subsequent crystal growth on returning to room temperature.

The anionic worm gels for these initial studies were based on nnPMAA $_{85}+(1-n)$ PGMA $\left._{48}\right]-$ PHPMA $_{140}$ compositions, where $n$ is varied from zero to 0.20 . These gels were prepared on a relatively large scale (7.1 g copolymer, $20 \% \mathrm{w} / \mathrm{w}$ ) using a somewhat shorter $\mathrm{PGMA}_{48}$ macro-CTA than that described in cases 1 and 2 above. This was expected to promote strong interactions between the worms and the growing calcite crystals owing to the protruding anionic $\mathrm{PMAA}_{85}$ stabilizer chains $^{59}$ while retaining access to a pure worm morphology. A PHPMA DP of 140 was required to access the worm region of the phase diagram, which is a little lower than the DP of 150 targeted in Figure 7 when using binary mixtures of $\mathrm{PGMA}_{62}$ and $\mathrm{PMAA}_{85}$ macro-CTAs. The successful preparation of PMAAcontaining worm gels using even more dissimilar macro-CTA DPs further demonstrates the efficacy of this binary macro-CTA approach.

A series of four anionic worm gels and a control non-ionic worm gel were characterized by rheology prior to crystallization studies. Figure 9A shows representative strain sweeps for each of these worm gels, along with a digital photograph illustrating the free-standing nature of the as-prepared gels (see inset). Clearly, increasing the $\mathrm{PMAA}_{85}$ content systematically reduces the gel strength from $\sim 4 \mathrm{kPa}$ to less than $300 \mathrm{~Pa}$ (at $1 \%$ strain). This is most likely because of the formation of shorter worms as a result of less efficient 1D fusion of the increasingly anionic spheres. Unfortunately, TEM evidence for this hypothesis cannot be obtained as the worms tend to dissociate into spheres on dilution (see Figure 9B). ${ }^{32}$ The thermoresponsive behavior of these worm gels was also assessed via rheology (Figure 10) on $20 \% \mathrm{w} / \mathrm{w}$ gels and via SAXS analysis of dispersions diluted to $5 \% \mathrm{w} / \mathrm{w}$ (Figure S1, ESI). It is well known that non-ionic PGMA-PHPMA worm gels undergo reversible degelation on cooling as a result of a worm-to-sphere transition, ${ }^{26}$ thus the effect of increasing the proportion of anionic PMAA chains on this morphological transition was investigated. For gels comprising less than 20 mol. \% PMAA ${ }_{85}$
macro-CTA, (de)gelation occurred at approximately $10^{\circ} \mathrm{C}_{\mathrm{C}}$ with

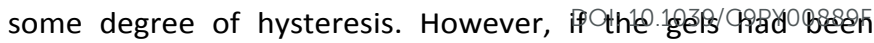
allowed to equilibrate for a longer time then it is likely that the original gel strengths should be recovered. ${ }^{32}$ For the 20 mol. \% $\mathrm{PMAA}_{85}$ sample, the inherently weaker nature of this gel makes interpretation of its rheological data more difficult.

Subsequently, crystal growth experiments were performed via the 'ammonium carbonate diffusion' method. ${ }^{72}$ Calcite crystals were allowed to grow over two days at $20^{\circ} \mathrm{C}$ within the worm gels, followed by extensive washing with methanol to remove the copolymer and SEM analysis of the remaining crystals (Figure 11). In the absence of any anionic carboxylate groups (Figure 11A), there is no effect on the equilibrium rhombohedral calcite crystal morphology. However, inclusion of just 5 mol. \% of the $\mathrm{PMAA}_{85}$ stabilizer within the worm corona has a large effect on the anionic nature of these nano-objects (see Zeta potential curves in Figure 9B). This drastically changes the crystal morphology, leading to the formation of polycrystalline spherulites in addition to modified single crystals (Figure 11B). The building blocks of these spherulites resemble small rhombohedral calcite crystals. Increasing the $\mathrm{PMAA}_{85}$ content up to $15 \%$ (Figure 11C) led to further modification of the spherulites, in which the building blocks are now modified rhombs, suggesting a strong interaction between the anionic gel components and the growing calcite. The single crystals are also modified: they possess smaller $\{104\}$ end-caps and smoother, more 'bullet-shaped' morphologies, consistent with carboxylate interaction with non-equilibrium facets and/or step edges.

Thus, controlling the bulk modulus and anionic character of these worm gels leads to pronounced variations in calcite crystallization and morphology. In future work, we will use such 'designer' gels for further crystal growth experiments to investigate the interplay between chemical functionality and nanoconfinement within a soft 3D matrix on crystallization.

\section{Conclusions}

In summary, using a binary mixture of an anionic and a non-ionic macro-CTA as a steric stabilizer during the RAFT dispersion polymerization of HPMA is a versatile method for the preparation of a wide range of anionic block copolymer nanoobjects with carboxylic acid functionality. Moreover, this approach provides excellent control over copolymer morphology, nano-object dimensions and surface functionality (with the latter parameter dictating the electrophoretic behavior of the nano-objects). In particular, thermoreversible anionic copolymer worm gels are expected to be useful model matrices for elucidating hitherto unknown 'design rules' in future biomineralization studies.

\section{Conflicts of interest}

There are no conflicts to declare. 


\section{Acknowledgements}

This work was funded by a joint National Science Foundation (NSF) and EPSRC Materials World Network (MWN) grant (DMR 1210304 and EP/J018589/1). SPA also acknowledges an ERC Advanced Investigator grant (PISA 320372) and an EPSRC Particle Technology Fellowship (EP/R003009/1). We thank Danielle Lieber for assistance with the crystallization experiments. We are grateful to Diamond Light Source for providing synchrotron beam-time (SM9490 and SM10237) and thank the personnel of 122 for their assistance. The authors are also grateful to ESRF for providing synchrotron beam-time (SC3864) and thank the personnel of BM26 for their assistance.

\section{Notes and references}

1. B. Charleux, G. Delaittre, J. Rieger and F. D'Agosto, Macromolecules, 2012, 45, 6753-6765.

2. M. J. Monteiro and M. F. Cunningham, Macromolecules, 2012, 45, 4939-4957.

$3 . \quad J .-T$. Sun, C.-Y. Hong and C.-Y. Pan, Polym. Chem., 2013, 4, 873-881.

4. N. J. Warren and S. P. Armes, J. Am. Chem. Soc., 2014, 136, 10174-10185.

5. S. L. Canning, G. N. Smith and S. P. Armes, Macromolecules, 2016, 49, 1985-2001.

6. M. J. Derry, L. A. Fielding and S. P. Armes, Prog. Polym. Sci., 2016, 52, 1-18.

7. A. B. Lowe, Polymer, 2016, 106, 161-181.

8. M. Lansalot and J. Rieger, Macromolecular Rapid Communications, 2019, 40, 1800885.

9. Z. An, Q. Shi, W. Tang, C.-K. Tsung, C. J. Hawker and G. D. Stucky, J. Am. Chem. Soc., 2007, 129, 14493-14499.

10. J. Rieger, C. Grazon, B. Charleux, D. Alaimo and C. Jerome, Journal of Polymer Science Part A-Polymer Chemistry, 2009, 47, 2373-2390.

11. S. Boisse, J. Rieger, K. Belal, A. Di-Cicco, P. Beaunier, M.-H. Li and B. Charleux, Chem. Commun., 2010, 46, 1950-1952.

12. Y. Li and S. P. Armes, Angew. Chem., Int. Ed., 2010, 49, 4042-4046

13. A. Blanazs, J. Madsen, G. Battaglia, A. J. Ryan and S. P. Armes, J. Am. Chem. Soc., 2011, 133, 16581-16587.

14. S. Sugihara, A. Blanazs, S. P. Armes, A. J. Ryan and A. L. Lewis, J. Am. Chem. Soc., 2011, 133, 15707-15713.

$15 . \quad$ C.-Q. Huang and C.-Y. Pan, Polymer, 2010, 51, 5115-5121.

16. W. Cai, W. Wan, C. Hong, C. Huang and C. Pan, Soft Matter, 2010, 6, 5554-5561.

17. W.-M. Wan and C.-Y. Pan, Polym. Chem., 2010, 1, 14751484.

18.

W.-M. Wan, X.-L. Sun and C.-Y. Pan, Macromolecular Rapid Communications, 2010, 31, 399-404.

19. C.-Q. Huang, Y. Wang, C.-Y. Hong and C.-Y. Pan, Macromolecular Rapid Communications, 2011, 32, 11741179.

20. L. Houillot, C. Bui, M. Save, B. Charleux, C. Farcet, C. Moire, J. A. Raust and I. Rodriguez, Macromolecules, 2007, 40, 6500-6509.

21. L. Houillot, C. Bui, C. Farcet, C. Moire, J. A. Raust, H. Pasch, M. Save and B. Charleux, ACS Appl. Mater. Interfaces, 2010, 2, 434-442.
22.

L. A. Fielding, M. J. Derry, V. Ladmiral, J. Rosselgong A. M. Rodrigues, L. P. D. Ratcliffe, S. Sugibara ande S. SP.YArmes, Chemical Science, 2013, 4, 2081-2087.

23. L. A. Fielding, J. A. Lane, M. J. Derry, O. O. Mykhaylyk and S. P. Armes, J. Am. Chem. Soc., 2014, 136, 5790-5798.

24. Y. Pei, L. Thurairajah, O. R. Sugita and A. B. Lowe, Macromolecules, 2014, 48, 236-244.

25. A. Blanazs, A. J. Ryan and S. P. Armes, Macromolecules, 2012, 45, 5099-5107.

26. A. Blanazs, R. Verber, O. O. Mykhaylyk, A. J. Ryan, J. Z. Heath, C. W. I. Douglas and S. P. Armes, J. Am. Chem. Soc., 2012, 134, 9741-9748.

27. M. K. Kocik, O. O. Mykhaylyk and S. P. Armes, Soft Matter, 2014, 10, 3984-3992.

28. J. R. Lovett, N. J. Warren, L. P. D. Ratcliffe, M. K. Kocik and S. P. Armes, Angewandte Chemie International Edition, 2015, 54, 1279-1283.

$29 . \quad$ J. R. Lovett, N. J. Warren, S. P. Armes, M. J. Smallridge and R. B. Cracknell, Macromolecules, 2016, 49, 1016-1025.

30. N. J. W. Penfold, J. R. Lovett, N. J. Warren, P. Verstraete, J. Smets and S. P. Armes, Polym. Chem., 2016, 7, 79-88.

31. N. J. W. Penfold, J. R. Lovett, P. Verstraete, J. Smets and S. P. Armes, Polym. Chem., 2017, 8, 272-282.

N. J. Warren, M. J. Derry, O. O. Mykhaylyk, J. R. Lovett, L. P. D. Ratcliffe, V. Ladmiral, A. Blanazs, L. A. Fielding and S. P. Armes, Macromolecules, 2018, DOI: 10.1021/acs.macromol.8b01617.

33. M. Semsarilar, E. R. Jones, A. Blanazs and S. P. Armes, Adv. Mater., 2012, 24, 3378-3382.

34. M. Semsarilar, V. Ladmiral, A. Blanazs and S. P. Armes, Polym. Chem., 2014, 5, 3466-3475.

35. A. A. Cockram, R. D. Bradley, S. A. Lynch, P. C. D. Fleming, N. S. J. Williams, M. W. Murray, S. N. Emmett and S. P. Armes, Reaction Chemistry \& Engineering, 2018, 3, 645657.

36. M. Semsarilar, V. Ladmiral, A. Blanazs and S. P. Armes, Langmuir, 2013, 29, 7416-7424.

37. M. Semsarilar, V. Ladmiral, A. Blanazs and S. P. Armes, Langmuir, 2012, 28, 914-922.

38. M. Williams, N. J. W. Penfold, J. R. Lovett, N. J. Warren, C. W. I. Douglas, N. Doroshenko, P. Verstraete, J. Smets and S. P. Armes, Polym. Chem., 2016, 7, 3864-3873.

39. N. J. W. Penfold, Y. Ning, P. Verstraete, J. Smets and S. P. Armes, Chemical Science, 2016, 7, 6894-6904.

40. N. J. W. Penfold, A. J. Parnell, M. Molina, P. Verstraete, J. Smets and S. P. Armes, Langmuir, 2017, 33, 14425-14436. L. Couvreur, C. Lefay, J. Belleney, B. Charleux, O. Guerret and S. Magnet, Macromolecules, 2003, 36, 8260-8267.

J. Ilavsky and P. R. Jemian, J. Appl. Crystallogr., 2009, 42, 347-353.

P. Cacioli, D. G. Hawthorne, R. L. Laslett, E. Rizzardo and D. H. Solomon, J Macromol Sci Chem, 1986, A23, 839-852.

C. L. McCormick and A. B. Lowe, Accounts of Chemical Research, 2004, 37, 312-325.

45. B. Akpinar, L. A. Fielding, V. J. Cunningham, Y. Ning, O. O. Mykhaylyk, P. W. Fowler and S. P. Armes, Macromolecules, 2016, 49, 5160-5171.

46. N. J. Warren, O. O. Mykhaylyk, D. Mahmood, A. J. Ryan and S. P. Armes, J. Am. Chem. Soc., 2013, 136, 1023-1033.

47. V. J. Cunningham, L. P. D. Ratcliffe, A. Blanazs, N. J. Warren, A. J. Smith, O. O. Mykhaylyk and S. P. Armes, Polym. Chem., 2014, 5, 6307-6317. 
48. M. J. Derry, L. A. Fielding, N. J. Warren, C. J. Mable, A. J. Smith, O. O. Mykhaylyk and S. P. Armes, Chemical Science, 2016, 7, 5078-5090.

49. L. P. D. Ratcliffe, A. Blanazs, C. N. Williams, S. L. Brown and S. P. Armes, Polym. Chem., 2014, 5, 3643-3655.

50. A. Hanisch, P. Yang, A. N. Kulak, L. A. Fielding, F. C. Meldrum and S. P. Armes, Macromolecules, 2016, 49, 192-204.

51. Y. Ning, L. A. Fielding, L. P. D. Ratcliffe, Y.-W. Wang, F. C. Meldrum and S. P. Armes, J. Am. Chem. Soc., 2016, 138, 11734-11742.

52. C. T. Hendley, L. A. Fielding, E. R. Jones, A. J. Ryan, S. P. Armes and L. A. Estroff, J. Am. Chem. Soc., 2018, 140, 79367945.

53. A. N. Kulak, R. Grimes, Y.-Y. Kim, M. Semsarilar, C. AnduixCanto, O. Cespedes, S. P. Armes and F. C. Meldrum, Chem. Mater., 2016, 28, 7528-7536.

54. Y. Y. Kim, M. Semsarilar, J. D. Carloni, K. R. Cho, A. N. Kulak, I. Polishchuk, C. T. Hendley, P. J. M. Smeets, L. A. Fielding, B. Pokroy, C. C. Tang, L. A. Estroff, S. P. Baker, S. P. Armes and F. C. Meldrum, Adv. Funct. Mater., 2016, 26, 13821392.

55. A. N. Kulak, M. Semsarilar, Y. Y. Kim, J. Ihli, L. A. Fielding, O. Cespedes, S. P. Armes and F. C. Meldrum, Chemical Science, 2014, 5, 738-743.

56. Y. Y. Kim, K. Ganesan, P. C. Yang, A. N. Kulak, S. Borukhin, S. Pechook, L. Ribeiro, R. Kroger, S. J. Eichhorn, S. P. Armes, B. Pokroy and F. C. Meldrum, Nat. Mater., 2011, 10, 890896.

57. Y. Ning, L. A. Fielding, J. Nutter, A. N. Kulak, F. C. Meldrum and S. P. Armes, Angewandte Chemie International Edition, 2019, 58, 4302-4307.

58. Y. Ning, L. Han, M. J. Derry, F. C. Meldrum and S. P. Armes, J. Am. Chem. Soc., 2019, 141, 2557-2567.

59. Y.-Y. Kim, L. A. Fielding, A. N. Kulak, O. Nahi, W. Mercer, E. R. Jones, S. P. Armes and F. C. Meldrum, Chem. Mater., 2018, 30, 7091-7099.

60. O. Wichterle and D. LíM, Nature, 1960, 185, 117.

61. H. Yasuda, M. Gochin and W. Stone, Journal of Polymer Science Part A-1: Polymer Chemistry, 1966, 4, 2913-2927.

62. M. W. Tibbitt and K. S. Anseth, Biotechnology and Bioengineering, 2009, 103, 655-663.

63. K. A. Simon, N. J. Warren, B. Mosadegh, M. R. Mohammady, G. M. Whitesides and S. P. Armes, Biomacromolecules, 2015, 16, 3952-3958.

$64 . \quad$ J. L. Drury and D. J. Mooney, Biomaterials, 2003, 24, 43374351.

65. S. Van Vlierberghe, P. Dubruel and E. Schacht, Biomacromolecules, 2011, 12, 1387-1408.

66. H. K. Henisch, Crystals in Gels and Liesegang Rings, Cambridge University Press, Cambridge, 1988.

67. E. Asenath-Smith, H. Li, E. C. Keene, Z. W. Seh and L. A. Estroff, Adv. Funct. Mater., 2012, 22, 2891-2914.

68. H. Li and L. A. Estroff, Adv. Mater., 2009, 21, 470-473.

69. H. Li, H. L. Xin, D. A. Muller and L. A. Estroff, Science, 2009, 326, 1244-1247.

70. Y. Ning, L. A. Fielding, K. E. B. Doncom, N. J. W. Penfold, A. N. Kulak, H. Matsuoka and S. P. Armes, Acs Macro Letters, 2016, 5, 311-315.

71. R. Verber, A. Blanazs and S. P. Armes, Soft Matter, 2012, 8, 9915-9922.

72. J. Ihli, P. Bots, A. Kulak, L. G. Benning and F. C. Meldrum, Adv. Funct. Mater., 2013, 23, 1965-1973. 


\section{Graphical Abstract:}

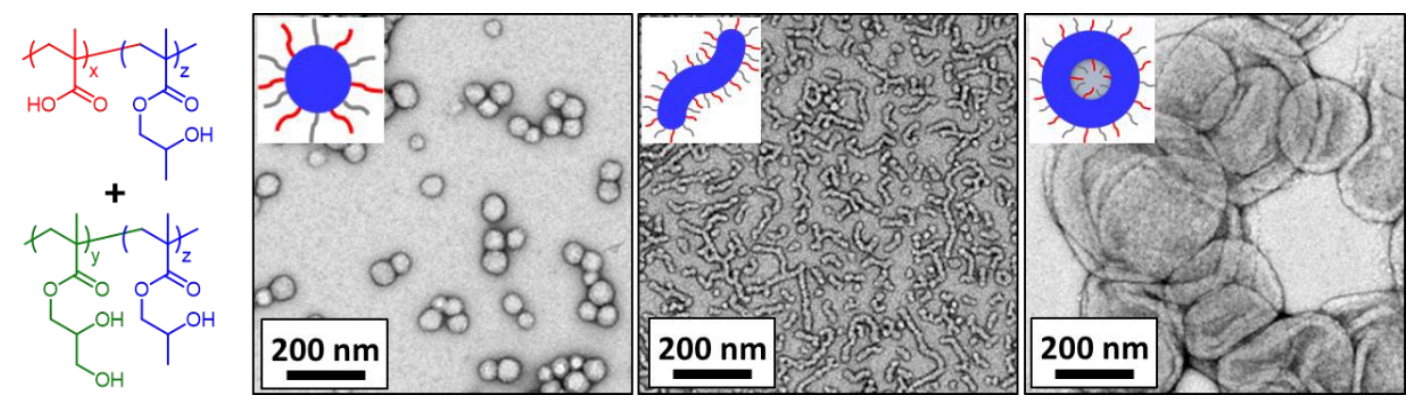

